\title{
A vida móvel das mulheres entre os bairros e as cidades: explorações antropológicas em fronteiras urbanas da Região Metropolitana de Belo Horizonte (Minas Gerais/Brasil) ${ }^{1}$
}

\author{
Candice Vidal e Souza ${ }^{2}$ \\ Pontifícia Universidade Católica de Minas Gerais, Brasil \\ candice.vidal@yahoo.com.br \\ Recibido: 25 de enero de 2017 \\ Aceptado: 17 de septiembre de 2017 \\ Disponible en línea: 30 de junio de 2018
}

\footnotetext{
1 Artigo de investigação científica e tecnológica. Versões anteriores desse trabalho foram apresentadas nos Congressos Internacionais da Latin American Studies Association (LASA) em 2015 (San Juan, Puerto Rico) e 2016 (New York, USA). Sou grata a Joanne Durchfort, coordenadora da Casa do Jardim, e à Fundação de Amparo à Pesquisa de Minas Gerais (FAPEMIG), que financiou a pesquisa inicial no Jardim Canadá em 2013.

2 Doutora em Antropologia Social, PPGAS / Museu Nacional / UFRJ. Professora do Programa de Pós-Graduação em Ciências Sociais da Pontifícia Universidade Católica de Minas Gerais (Brasil).
} 


\title{
La vida móvil de las mujeres entre los barrios y las ciudades: exploraciones antropológicas en fronteras urbanas de la Región Metropolitana de Belo Horizonte (Minas Gerais/Brasil)
}

\section{Resumen}

El artículo presenta los resultados preliminares de la investigación antropológica en dos barrios de la Región Metropolitana de Belo Horizonte, en la cual los desplazamientos son descritos analiticamente como prácticas de movimiento situadas en el espacio social, atentando contra los efectos de género y lugar de residencia en los trayectos de los sujetos en las ciudades. Los barrios del Jardim Canadá y Água Limpa están localizados a lo largo de la carretera BR-040, donde hay viviendas y servicios para personas de clase media y grupos de ingresos menores. En ese contexto heterogéneo de expansión urbana se enfoca la movilidad de las mujeres y sus familiares que migraron de otros lugares y hoy realizan viajes rutinarios para cumplir responsabilidades de trabajo y de servicios personales. Las prácticas de movilidad serán pensadas en relación al contexto metropolitano y las modulaciones valorativas asociadas al movimiento, en busca de una vida mejor y de la ciudad posible, relacionando las trayectorias de los individuos al espacio-tiempo de las fronteras urbanas. Palabras clave: movilidades femeninas; fronteras urbanas; región metropolitana de Belo Horizonte

\section{The mobile life of women between neighborhoods and cities: anthropological explorations in the urban borders of the metropolitan region of Belo Horizonte (Minas Gerais, Brazil)}

\begin{abstract}
The article presents the preliminary results of an anthropological research carried out in two neighborhoods of the metropolitan region of Belo Horizonte. There, displacements are analytically described as movement practices located in the social space, which act against the effects of gender and residence in the journeys of subjects in the cities. The neighborhoods of Jardim Canada and Água Limpa are located along highway BR-040, where there are housing and utilities for middle class and lower income groups. In this heterogeneous context of urban expansion, the focus is on the mobility of women and their families, who migrated from other places and now make routine trips to fulfill work and personal service responsibilities. The mobility practices are thought in relation to the metropolitan context and the changes in valuation associated with the movement, leading to a search of a better life and the city that could be, intertwining the trajectories of individuals to the space-time of the urban borders.
\end{abstract}

Keywords: female mobility; urban borders; metropolitan region of Belo Horizonte

\section{A vida móvel das mulheres entre os bairros e as cidades: explorações antropológicas em fronteiras urbanas da Região Metropolitana de Belo Horizonte (Minas Gerais/Brasil)}

\section{Resumo}

O artigo apresenta os resultados preliminares de pesquisa antropológica em dois bairros da Região Metropolitana de Belo Horizonte, na qual os deslocamentos são descritos analiticamente como práticas de movimento situadas no espaço social, atentando para os efeitos de gênero e local de moradia nos trajetos dos sujeitos nas cidades. Os bairros do Jardim Canadá e Água Limpa estão localizados ao longo da estrada BR-040, onde existem residências e serviços que atendem às classes médias e a grupos de menor renda. Nesse contexto heterogêneo de expansão urbana, enfoca-se a mobilidade de mulheres e seus familiares que migraram de outros locais e hoje realizam viagens rotineiras para cumprir responsabilidades de trabalho e de cuidado. As práticas de mobilidade serão pensadas em relação ao contexto metropolitano e às modulações valorativas associadas ao movimento em busca da vida melhor e da cidade possivel, relacionando as trajetórias dos indivíduos ao espaço-tempo das fronteiras urbanas. Palavras-chave: mobilidades femininas; fronteiras urbanas; região metropolitana de Belo Horizonte 


\section{Introdução}

A expansão das cidades brasileiras realiza-se notadamente pela ocupação de novos espaços por meio do loteamento de terrenos para a construção de residências particulares, combinadas eventualmente com atividades comerciais, industriais e de lazer. O projeto de construir a própria casa é a causa significativa de muitos movimentos de famílias das classes populares pelo entorno dessas cidades em busca de espaços para comprar ou invadir. Como mostram vários estudos sobre os empreendimentos econômicos das classes populares brasileiras, a posse da casa e sua (re)construção permanente materializa os esforços do grupo doméstico em busca da boa vida (Woortmann, 1982; Motta, 2014). A intenção deste artigo é considerar os atos de deslocamentos dos moradores de áreas de expansão das franjas metropolitanas até lá chegarem e os movimentos rotineiros enquanto moldam seu viver nos bairros, em relação com o projeto de vida familiar. Deve ficar claro que as mobilidades corporais são privilegiadas como acesso à experiência dos moradores dessas áreas. Seguindo Cresswell (2010), sabe-se que a mobilidade (de pessoas, ideias e coisas) é um fato geográfico que articula o movimento, sua representação e prática, a ser compreendido no curso da vida cotidiana em sua dimensão de poder.

Nos lugares por onde pesquiso, procuro conhecer o que as imaginações do futuro fazem no presente das mulheres em termos de motivações para mover-se. O lugar de morada a ser conquistado diariamente se faz não apenas com a posse de um lote, com uma casa, mas também por intermédio de inúmeras ações de garantia do funcionamento da vida; tais ações demandam movimentos que expressam a "espacialização da esperança" (Pels, 2015).

Essas fronteiras urbanas ou "vazios" a serem ocupados em áreas novas para onde a cidade se espraia se caracterizam pela oferta precária de meios de deslocamento, pois são regiões desprovidas de serviços públicos de maneira geral. As lutas dos moradores por instalação de energia elétrica, fornecimento de água, 
coleta de lixo e outros beneficios incluem também a demanda por mobilidade.

Desde algumas décadas, as áreas localizadas ao longo da BR040, na região metropolitana de Belo Horizonte, vêm sendo ocupadas por residências e serviços que atendem às classes médias e a grupos de menor renda. As variantes específicas desse processo têm sido estudadas por sociólogos, economistas e geógrafos (ver Pires, 2003; Costa, 2006; Andrade, Mendonça e Diniz, 2015; Andrade, 2016), compreendidas, sobretudo, pela chave analítica da segregação socioespacial. Neste trabalho, sigo a trilha dos estudos sobre a expansão urbana enquanto prática de viver de certos sujeitos cujas ações fazem existir esses espaços novos que são ocupados e construídos cotidianamente no enfrentamento de condições materiais e legais adversas, as quais podem se alterar rapidamente ou não (Telles, 2010; Birman, Leite, Machado e Carneiro, 2015). Importa afirmar também que esses núcleos urbanos em crescimento permanente são compreendidos nas novas configurações de áreas distantes do centro polarizador de uma região metropolitana, que não resultam necessariamente em áreas precárias e estagnadas em termos socioeconômicos e urbanos, tal como a definição hegemônica de "cidade-dormitório" representa experiências urbanas como a dos bairros em estudo. A região em questão exemplifica a "heterogeneidade e a complexidade das redes e formas urbanas", que configuram outros cenários e funcionamentos da vida metropolitana que não podem ser compreendidos pelo modelo clássico centro-periferia (Ojima, Marandola Jr., Pereira e Silva, 2010, p. 409), o qual descreve tais lugares com características de não-cidade.

Por essa visada analítica, vai-se pensar sobre as condições de mobilidade atuais e passadas das mulheres que residem em dois bairros da região metropolitana de Belo Horizonte (Jardim Canadá e Água Limpa), considerando os deslocamentos cotidianos como práticas de movimento de pessoas situadas no espaço social e físico as quais sofrem modulações de acordo com gênero, idade, composição do grupo doméstico, condições financeiras e local de moradia. 


\section{Os cenários da mobilidade}

Os bairros do Jardim Canadá e Água Limpa, situados nos municípios de Nova Lima e Itabirito, estão articulados social e economicamente com condomínios fechados (murados e vigiados) para públicos de alta renda, fábricas, atividade mineradora e serviços variados (comércio, escolas, policiamento, administração municipal etc.) (ver figura 1).
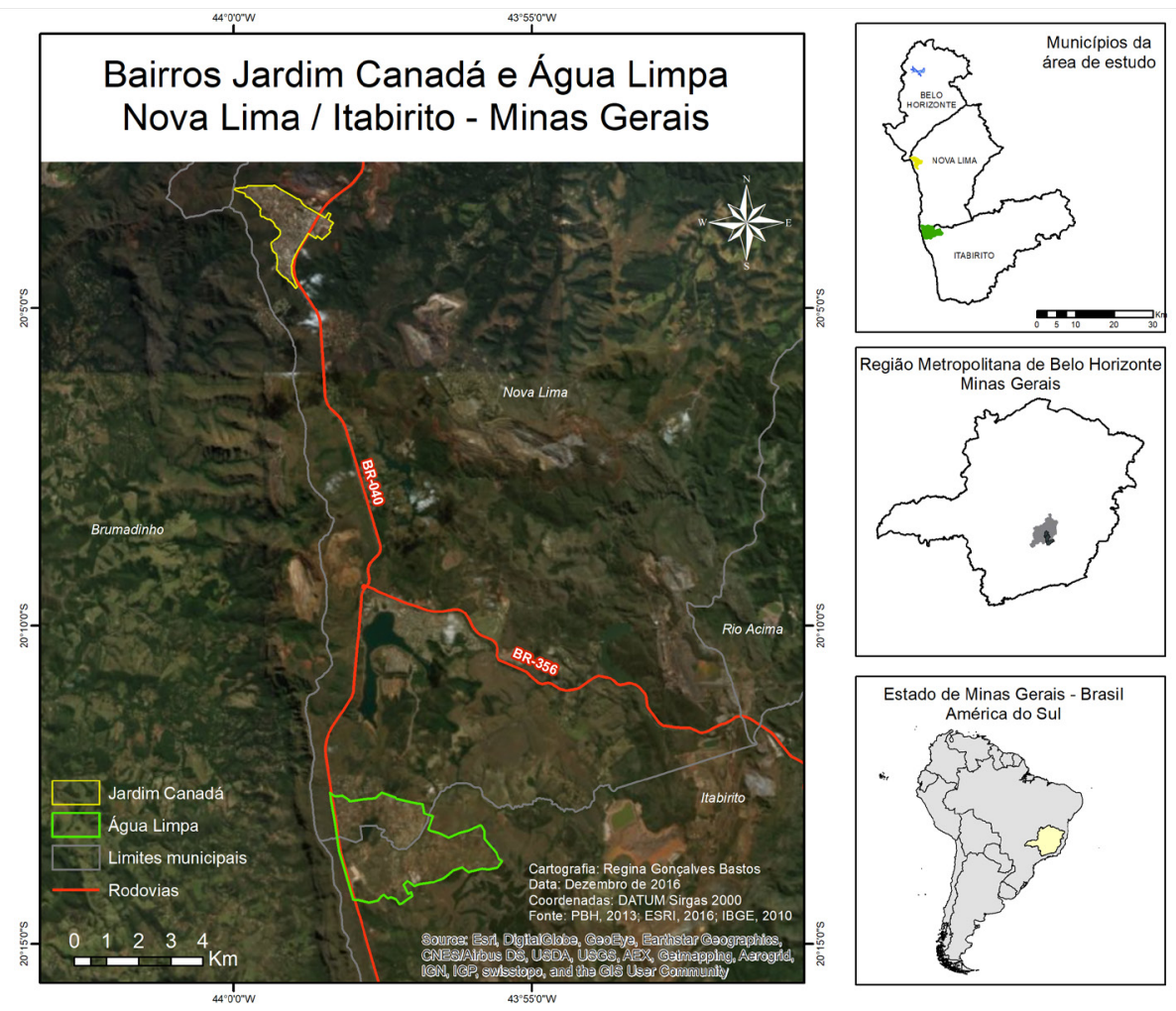

Figura 1. Bairros Jardim Canadá e Água Limpa, Nova Lima / Itabirito - Minas Gerais

Fonte: PBH, 2013; ESRI, 2016; IBGE, 2010.

Nessa região de confluência de quatro municípios, podem ser observados os fenômenos de periurbanização, de interconexões entre atividades e espaços urbanos, de interações entre grupos sociais distintos, os quais resultam em um cenário de novas composições urbanas (Moura, 2010). Considerando que esses cenários de vida 
são construídos pelas formas do habitar e pelo emaranhado dos deslocamentos, são investigadas as experiências de mobilidade de mulheres, especialmente aquelas que fazem viagens interurbanas e intra-bairros rotineiras para cumprir responsabilidades de trabalho e de cuidados dos filhos e da casa. O objetivo é realizar descrições analíticas de suas constelações de mobilidade conforme proposto por Tim Cresswell (2010). As histórias sobre quem, como, quando e para que se move foram colhidas em conversas ocorridas em encontros pelos bairros; elas não resultam de acompanhamentos de trajetos diários, como realizado por outras pesquisadoras (Kusenbach, 2003; Jirón, 2011).

Os deslocamentos de mulheres pelos espaços das cidades, entre suas casas, vizinhanças, escolas, lojas, ruas e locais de trabalho remunerado, para realizar as atividades que envolvem interação com os equipamentos urbanos, os diversos meios de transporte a seu alcance e com outros sujeitos, especialmente homens adultos, que compartilham a cidade com elas, são uma faceta da vida social que vem sendo retirada da invisibilidade há alguns anos, sobretudo a partir da contribuição de estudos de geógrafas feministas (Law, 1999). As pesquisas que consideram a dimensão de gênero (entendida aqui como relações entre mulheres e homens num dado tempo e lugar) e as diferenças de práticas de mobilidade de mulheres, especialmente as que realizam viagens urbanas rotineiras para cumprir responsabilidades de cuidados dos filhos e da casa, têm proliferado em relação a diversos contextos empíricos (Little, Peake e Richardson, 1988; Uteng e Cresswell, 2008; Jirón, 2010; Vega Centeno, 2010). Esses trabalhos redirecionam a ênfase da pesquisa sobre mobilidades urbanas para eventos mais variados que os deslocamentos casa-trabalho, temas de pesquisas já realizadas em Belo Horizonte (Montal'vão Neto, 2009; Leiva, 2015; Souza, 2015).

Os dois bairros estão interligados pela rodovia BR-040, que liga Belo Horizonte ao Rio de Janeiro. Essa estrada de alta velocidade é duplicada até o Jardim Canadá, tornando-se uma pista de quatro faixas já próximo à entrada para Água Limpa. Essa estrutura viária configura aquilo que Pablo Vega Centeno (2010) chama de 
"territorios de la movilidad", graças aos quais "la articulación de este conjunto de destinos se organiza" (p. 54).

Nesses contextos da cidade em processo de se fazer, como caracteriza Michel Agier (2015), a intenção é compreender em que a configuração da cidade em processo de construção pode ensinar sobre as características sociológicas do movimento em suas dimensões de gênero, em particular nesses ambientes de dinamismo econômico e populacional que são as fronteiras urbanas, lugares de reinvenção das formas de viver e de morar.

Para realizar tal intento, toma-se a experiência feminina de deslocamentos de modo ampliado, considerando suas histórias migratórias (locais de moradia antes de Jardim Canadá e Água Limpa) e as conexões atuais com o entorno do bairro, ou seja, como se relacionam com pessoas, serviços e lugares situados em outras regiões mais ou menos próximas de seu local de moradia.

A condição que unifica as participantes da pesquisa é o fato de serem moradoras do Jardim Canadá ou de Água Limpa. Embora a pesquisa se dedique especialmente às mulheres, considero que a sua situação não deve ser tratada isoladamente da composição e dinâmica de relações de seu núcleo familiar, de seus outros parentes (moradores ou não dos bairros estudados), amigos e vizinhos.

A pesquisa de campo tem sido realizada por meio de visitas aos bairros, para o quais me desloco dirigindo meu próprio carro; costumo andar a pé pelas ruas e quarteirões do bairro. Posso dizer que minha posição de pesquisa se assemelha à "observação flutuante" proposta por Colette Pétonnet (1982). Enquanto visitante ocasional, porém constante, é que converso com as moradoras. Em verdade, não se configura como uma etnografia comme il faut (Ingold, 2014).

No Jardim Canadá, bairro onde iniciei pesquisas sobre ocupação urbana em 2013, minha permanência maior tem sido na Casa do Jardim, organização não-governamental que faz o acompanhamento escolar e desenvolve atividades recreativas e culturais 
com crianças mais pobres do bairro, e nas atividades de artesanato com mulheres no Centro de Referência da Assistência Social (CRAS) do Jardim Canadá. Em tais encontros, conversamos sobre as condições de mobilidade que mulheres de diferentes idades e tempo de moradia no bairro experimentam ao longo de suas rotinas atuais e passadas.

Em meados de 2016, iniciei a pesquisa de campo em Água Limpa, distante 15 quilômetros do primeiro bairro. Minha referência é o local onde funciona o Posto de Saúde, o Centro de Assistência Social (no qual trabalham duas assistentes sociais deslocadas pela Prefeitura de Nova Lima do Jardim Canadá para Água Limpa) e a sede de duas associações comunitárias do local. Nesse caso, permaneço por lá e encontro as frequentadoras do local. Os relatos sobre o cotidiano das mulheres e suas famílias são obtidos nesse local de trânsito que significa a referência e apoio dos moradores do bairro, mesmo daqueles que moram no setor mais precário em termos de assistência e serviços, que oficialmente se situa em outro município. Essa parte do bairro corresponde à área de ocupação mais antiga, próxima a um antigo hotel e à lagoa onde existe um balneário desativado que deu origem à ocupação dos terrenos ainda na década de 1950. Os tempos de ocupação dos terrenos nos bairros são relevantes na descrição sociológica dos lugares e das mobilidades, pois as condições de moradia, de urbanização e de transporte interferem na capacidade dos indivíduos para realizar movimentos para além de suas casas. No caso de Água Limpa, as casas mais distantes estão no local chamado Lagoa Seca, onde se situa o ponto final do ônibus coletivo. Mais adiante estão os moradores das colinas já situadas no município de Itabirito, onde a precariedade de acesso a água, energia elétrica e transporte público é notável.

Considerando-se o aspecto legal, o loteamento do bairro Jardim Canadá foi aprovado na Prefeitura de Nova Lima com 3773 lotes em 22/08/1958. A efetiva ocupação dos terrenos foi acontecendo nas décadas posteriores, com episódios como a vinda dos canadenses para trabalhar na mina de ouro de Morro Velho em Nova Lima e as 70 casas construídas para policiais de Belo Horizonte 
nos anos 1990. De acordo com relatório produzido por Durchfort (2013), a população do Jardim Canadá era de 564 pessoas em 1991; em 2010 contava-se 8265 residentes no bairro e quase 1000 empresas registradas.

O loteamento Água Limpa, embora não conste da listagem oficial da Prefeitura de Nova Lima, foi aprovado em nome da Construtora Alfa com 3471 lotes (Pires, 2003, pp. 246-251). Falase no bairro que a construtora desistiu do empreendimento e os herdeiros não reivindicaram a posse dos terrenos. Muitos dos lotes ocupados próximos à lagoa foram cercados após a confirmação nos cartórios do município de que pertenciam à construtora. Assim, são tratados como terras sem dono efetivo, podendo os ocupantes demandarem no prazo de alguns anos o reconhecimento da posse por usucapião. O crescimento de Água Limpa foi acelerado a partir de 2010, com estimativas de 3500 moradores na área de Nova Lima e 1500 na área pertencente a Itabirito (Durchfort, 2015). Essa situação atual difere totalmente da paisagem observada por Cláudia Pires: "o balneário Água Limpa, na década de 90, contava com 3466 lotes vagos, não dispondo de água nem de luz elétrica instalada" (Pires, 2003, p. 252).

O cenário por onde transitam as mulheres que conheço se transforma a cada dia com a construção de novas casas, abertura de comércio variado, ruas de terra, vans escolares e poucos ônibus, carros mais velhos e empoeirados. Ampliou-se o acesso (legal e/ou improvisado) à água e à luz elétrica; no entanto, várias famílias passam os dias a contornar as carências de toda ordem (desemprego, escola, luz elétrica, água, assistência médica e social).

As relações entre os dois bairros são marcantes, construindo vínculos de emprego, de estudo e de socialidade (relações de amizade e parentesco, templos religiosos, serviços de saúde e assistência social) que justificam deslocamentos em todos os dias da semana. São comuns as histórias de moradores do bairro Jardim Canadá que mudaram para Água Limpa após comprar lotes, invadir terrenos como investimento ou para construção de casa própria. 
Normalmente estão deixando as despesas com aluguel para trás ou a moradia em casas cedidas ou compartilhadas com a família. Ir para mais longe significa partir em busca de um futuro mais seguro, porém os laços se mantêm. As crianças estudam no Jardim Canadá ou no Condomínio Miguelão, dependendo do transporte escolar oferecido pela Prefeitura de Nova Lima, os serviços de compras mais diversificados estão no Jardim Canadá, as igrejas e os centros de saúde, o posto policial a rede de assistência social e inúmeros projetos educativos e culturais de organizações não-governamentais têm sede no Jardim Canadá e, principalmente, os empregos estão concentrados no bairro de ocupação mais antiga.

É exemplar desse trânsito diário o caso de Shirley, nascida em Santa Maria do Suaçuí (MG), que morava no Jardim Canadá e mudou-se para Água Limpa há pouco tempo. Ela e o marido trabalhavam no Jardim Canadá, onde o filho de 11 anos também estudava. Quando acabava seu turno de trabalho e a escola do filho, ficavam na casa da sogra como ponto de apoio até o marido concluir sua jornada de trabalho. Assim podiam todos voltar para casa de carro. Esse arranjo era instável e foi reinventado em novas condições, pois Shirley tem um bebê de poucos meses e a sogra pretende alugar a casa e mudar para o interior. Diante das dificuldades de transporte e da nova situação do filho mais velho agora estudar em Belo Horizonte, a família resolveu retornar para o Jardim Canadá e morar em uma casa alugada, enquanto a nova casa de Água Limpa foi alugada. A proposição de Peter Adey (2006) de que as mobilidades e as imobilidades são relacionais e relativas é oportuna para a análise desta e de várias outras histórias que se seguem.

O Jardim Canadá aparece em algumas falas escutadas como modelo para o bairro de Água Limpa. É a referência mais próxima para a imaginação de planos de mudança de local de moradia no rumo sul, para o bairro mais distante. Como me contou a agente de saúde que mora em Água Limpa desde o início de seu casamento há 25 anos, as pessoas costumam falar "Estou no Canadá de novo...", "Água Limpa hoje é o Canadá há dez anos, sem luz, sem água". Ou como escutei uma assistente social repetir um comentário de que 
“o Jardim Canadá era uma Água Limpa". Essa expectativa orienta os projetos de vida de quem se aventura a abrir novas fronteiras urbanas nesse bairro que fica atrás de uma fábrica da Coca-Cola (FEMSA) inaugurada em 2015, mas que não possui uma escola para suas crianças. Para aqueles que chegaram a Água Limpa desde o Jardim Canadá, fica mais claro que (quase sempre) é uma migração sem retorno, pois normalmente abandonaram casas de aluguel para fazer a sua própria morada. Sem que para tanto, tenham que ter abandonado seu emprego e/ou relações de amizade e parentesco.

\section{Fronteiras urbanas e mobilidades das mulheres}

A configuração socioespacial da região onde se situam os bairros escolhidos como ponto de apoio para a observação antropológica constitui um dado de interesse para estudar conexões entre trajetórias de deslocamento de mulheres (com e sem filhos), residentes em áreas próximas, porém desiguais em termos de condições urbanas e sociais. Os condomínios que mantêm relações mais próximas com os bairros são Retiro das Pedras, Miguelão, Morro do Chapéu, Alphaville, Pasárgada e Ville des Lacs (vizinho do bairro Água Limpa).

A aproximação antropológica ao cotidiano das atividades e deslocamentos das pessoas que moram nos bairros escolhidos parte da definição ampla de movimentos, pensando-os para além dos chamados deslocamentos pendulares (casa-trabalho-estudo), conforme recomendam vários pesquisadores (Law, 1999; Vega Centeno, 2010; Hanson e Pratt, 1995).

Outro ponto relevante é a própria caracterização dos locais, definidos como periferias (no caso dos dois bairros, situados nas chamadas novas periferias ricas) de Belo Horizonte em vários trabalhos (por exemplo, Bhering e Mont-Mór, 2006; Costa, 2006; Andrade, Mendonça e Diniz, 2015; Andrade, 2016) ou novas centralidades periféricas, em referência ao Jardim Canadá (Craveiro e Linhares, 
2006). Essa designação remete comumente a uma série de sentidos relativos a exclusão, carências e negatividade; enquanto a escuta das histórias de moradoras tem me falado de verdadeiras aventuras em busca de nova vida, da satisfação em conquistar um novo lugar de morada e do impeto em construir um ambiente comum de existência. Nesse sentido, a compreensão das andanças populares nos trabalhos de André Dumans Guedes $(2013,2014)$ é mais compativel com a realidade desses lugares de gente que anda entre cidades e bairros, dentro e fora da Região Metropolitana de Belo Horizonte. A ideia de fronteiras urbanas parece ser mais acurada para conceituar essa configuração de habitar e mover-se que investigo, seguindo-se o ânimo expresso pelos agentes dos deslocamentos. Esta escolha analítica é mais positiva (quer dizer, com ênfase em aspectos da vida que não se definem pela falta) e menos dualista (centros e periferias) que a linhagem de debates sobre segregação socioespacial tem oferecido (exceções relevantes em Telles, 2010; Motta, 2014; e Birman, Leite, Machado e Carneiro, 2015). Por essas razões, as discussões sobre periurbanização (Girola, 2008) e composições urbanas (Moura, 2010) são mais adequadas para uma antropologia das vidas móveis em áreas de fronteiras urbanas.

Nos bairros Jardim Canadá e Água Limpa, observa-se facilmente as conexões rotineiras de trajetos de deslocamento entre os bairros para atividades de trabalho, estudos e serviços comerciais. É comum que as viagens sejam motivadas por redes familiares e de interconhecimento com moradores do bairro mais antigo que começam a construir no local de ocupação mais recente, devido à disponibilidade de terrenos mais baratos ou passiveis de ocupação. Os deslocamentos acontecem devido aos laços com atividades que acontecem em condomínios fechados, empresas, fábricas e mineração de extração de ferro.

Desse modo, cabe seguir as ideias de Tim Ingold de que as vidas se conduzem por perambulatory movements, pois "lives are led not inside places but through, around, to and from them, from and to places elsewhere" (Ingold, 2011b, p. 148). A pista analítica é que os trajetos são ocorrências para os habitantes que se movem, os quais são "narrated like stories". Assim, "every place, as a gathering of 
things, is a knot of stories" (Ingold, 2011b, p.154). Os lugares enfocados aqui são definidos por meio de uma perspectiva sobre espaço que o trata não como mera superfície para a vida social, mas como encontro de histórias. Nos termos de Doreen Massey, "imagining the space as a simultaneity of stories-so-far" (Massey, 2013, p. 29).

Este artigo se alinha aos novos rumos da pesquisa sobre os lugares, definidos por Nigel Thrift, em consonância com Tim Ingold, como "dwelling perspective, based upon the primacy of practices" (Thrift, 1999, p. 308). Assim, "it follows that a place is not in space, but is a means by which space is produced as a plenitude of different relations" (Thrift, 1999, p. 310; grifos no original). Essa visão se contrapõe a uma "building perspective", na qual "space and time are neutral grids, or perhaps containers. Over which and in which meaning is 'placed"' (Thrift, 1999, p. 301).

O interesse principal é a situação atual dos indivíduos e suas famílias, mas para compreendê-la precisamos considerar as trajetórias anteriores de deslocamento nos bairros e entre os dois bairros (mudanças de lugares de moradia), como também entre cidades da região metropolitana, do estado de Minas Gerais e de outras regiões do Brasil. O conhecimento etnográfico já existente apresenta as formas de construção da vida (por exemplo, Borges, 2003) que em vários aspectos podem ser comparados com processos de ocupação e transformação dos lugares de moradia (o lote, o barraco, a casa, a rua, o bairro) em outras regiões economicamente dinâmicas do Brasil.

Entre moradoras do Jardim Canadá e Água Limpa, as histórias mais comuns são de partida da terra onde nasceram, em outros estados brasileiros ou em outras cidades de Minas Gerais. ${ }^{3}$ Dona Maria, que chegou ao Jardim Canadá em 1984 com três filhos e o marido, já tinha uma irmã morando no local. Nasceu em Santa Maria do Suaçuí (MG) e morava no Espírito Santo. O marido

\footnotetext{
Aqui há um contraste em relação aos contextos apresentados por Larsen, Axhausen e Urry (2006) nos quais a mobilidade residencial é associada a pessoas de altos níveis educacionais. Estamos a falar de brasileiros de baixa escolaridade e pouca qualificação profissional, que são os personagens dos circuitos de deslocamentos regionais e urbanos vigorosos ao longo de nossa história.
} 
arranjou emprego no Condomínio Retiro das Pedras, ao qual se pode chegar a pé. Conta que o marido e os filhos sempre encontraram emprego no bairro e não tiveram necessidade de se deslocar para trabalhar em outros locais distantes. Dona Amália nasceu em Aracaju (SE) e morava em Juiz de Fora (MG), quando mudou para o Jardim Canadá há 22 anos. O marido policial comprou uma das casas construídas para essa categoria no loteamento. Ela também trabalhava como passadeira de roupas no Condomínio Retiro das Pedras, ao qual chegava caminhando. De vez em quando conseguia carona com os patrões que eram comerciantes no bairro. Para fazer as compras do mês, ia até o centro de Belo Horizonte no ônibus, que tinha apenas dois horários por dia. Pagava um táxi até o Jardim Canadá para transportar as compras. Essas duas moradoras antigas recordam do tempo de carências de água, luz, comércio básico e transporte. D. Maria tem autoridade para retrucar aqueles que hoje reclamam da distância quando tomam o ônibus para Belo Horizonte e diz: "Agora você tá na cidade!".

Em Água Limpa, reencontra-se as histórias de fluxos, originados em locais mais ou menos distantes dali (bairros de Belo Horizonte, cidades do interior mineiro, do Maranhão e do Ceará). Dona Lita nasceu em Jeceaba (MG) e morou 24 anos em casa cedida do Condomínio Miguelão; em 2010 comprou lote em Água Limpa e passou a morar de aluguel enquanto sua casa era construída. Em 2011, mudou para sua casa no lote onde estão também as casas de seus filhos, inclusive a filha que é mãe de um menino e trabalha todos os dias em Belo Horizonte, tomando o ônibus de 5:40h da manhã e retornando às 19:30h. Enquanto morava no condomínio, fazia compras no centro de Belo Horizonte, perto da Rodoviária e depois passou a comprar no Jardim Canadá, com a melhora na oferta de lojas e supermercados. Como é professora da escola municipal do Condomínio Miguelão, aproveita o transporte escolar dos alunos para ir ao trabalho no turno da manhã.

Certamente, os trajetos e suas motivações seguem um fator crucial nesses contextos: o emprego. As mulheres e os homens empregados estão mais sujeitos aos desafios cotidianos da mobilidade em 
locais mais longinquos ou com precária disponibilidade de meios de transporte, resultando em estratégias variadas de deslocamento. ${ }^{4}$ A história de Lilian, que morava em bairro da região Oeste de Belo Horizonte quando era solteira com filhos e está em Água Limpa há 4 anos, ilustra uma experiência ocasional de hipermobilidade. Nos primeiros tempos, viveu de aluguel enquanto o marido pedreiro contruía a casa com a sua ajuda. Hoje usa água do poço do vizinho, pelo qual paga $R \$ 50,00$ por mês. Para ter luz elétrica, gastou $R \$ 4000,00$ em material para "puxar o gato" (ligação clandestina) da empresa CEMIG (Companhia Energética de Minas Gerais). Ela trabalhou em Belo Horizonte como cuidadora de idosos até os oito meses de gravidez do filho agora bebê. Enquanto isso, o filho de 11 anos chegava da escola e ficava em casa. O seu pai trabalhava como pedreiro nas proximidades, podendo socorrê-lo em caso de necessidade. Deslocava-se de moto pela rodovia e foi proibida pelo médico por causa dos riscos na estrada. Quando vinha de Belo Horizonte, conseguia fazer compras no Jardim Canadá e encher o baú da traseira de sua moto. Quando a encontrei em 2016, Lilian estava desempregada, pois precisava cuidar dos filhos e tinha vendido sua moto e comprado um carro que raramente funciona. Quando necessita, recorre ao carro do vizinho em emergências de saúde. De outro modo, sua única opção é o ônibus rodoviário para o qual gasta mais de $\mathrm{R} \$ 11,00$ em cada viagem. Para se ter uma ideia da velocidade da ocupação de Água Limpa, Lilian me contou que, quando ela chegou, a sua casa foi a primeira da quadra. Hoje em dia só resta um lote vago.

O capital de mobilidade dos indivíduos, expresso pelo conceito de motilidade $^{5}$ (Kaufmann, Bergman e Joye, 2004; Flamm e Kaufmann, 2006) é alterado por transformações em seu próprio arranjo doméstico (idade dos filhos, condições de emprego) e por novas configurações na estrutura de transporte local (disponibilidade de linhas de ônibus, por exemplo). Há famílias nas quais ambos os cônjuges estão desempregados, reduzindo seus deslocamentos motorizados

4 Como registrado em outras situações na América Latina (Hernandez e Titheridge, 2016), há presença de alternativas informais de transporte cumprindo funções complementares aos meios formais em Água Limpa e no Jardim Canadá.

5 De acordo com Flamm e Kaufmann (2006), "motility can be defined as the capacity of entities (e.g. goods, information or persons) to be mobile in social and geographic space, or as the way in which entities access and appropriate the capacity for socio-spatial mobility according to their circumstances" (p. 750). 
e programando as saídas para mais longe. Encontram-se, de fato, em relativa imobilidade (Adey, 2006), muitas vezes dependendo do auxílio da assistência social para comparecer a entrevistas de emprego, atendimento médico ou cursos profissionalizantes em outros locais. Em consequência, os deslocamentos intra-bairro a pé ou por meio de caronas com vizinhos são mais numerosos.

As formas de mobilidade da população de baixa renda, a qual pertencem as pessoas de quem falo aqui, podem ser descritas em termos dos lugares por onde vão e dos modos de transporte utilizados. Como observou Sebastian Ureta (2008) em Santiago, esses aspectos são mais decisivos para definir a exclusão social que propriamente a imobilidade. Desse modo, os recursos de tempo e dinheiro para a mobilidade são empregados rigorosamente para viagens compulsórias, restringindo perambulações por lugares pouco visitados no dia a dia que podem oferecer oportunidades de aprendizagem e experiências diversas. ${ }^{6}$

Nas histórias de mulheres, suas famílias nucleares ou extensas, ou dos grupos domésticos, são capturadas as narrativas de deslocamentos e mudanças na vida, mas também a compreensão nativa dos percursos e suas características de socialidade. Como pude constatar dentro do ônibus que segue do centro de Belo Horizonte, passa pelo Jardim Canadá e segue até Água Limpa, explorar os contextos da mobilidade nas sociedades metropolitanas e suas áreas espacialmente mais dispersas é analiticamente produtivo para a compreensão da socialidade nos trânsitos pelos lugares, desde que se tome a relação entre exclusão social e acesso a recursos de mobilidade como sendo dinâmica, pois as condições individuais, familiares e sociais estão sujeitas a mudanças rápidas; algumas delas provocadas exatamente pela politização da mobilidade nas ações de moradores junto a empresas de transporte e governo municipal, como aconteceu em Água Limpa recentemente e no Jardim Canadá em outros tempos.

6 Sobre a repetição dos trajetos e o valor moral atribuído às mulheres que circulam na cidade para cumprir obrigações entre a casa e o trabalho, ver a noção de percursos horizontais que acontecem como se fossem em túnel (Jirón, 2010) e as discussões de Lênin Pires (2013) sobre movimentos de usuárias de transporte público. Percebe-se aqui que há significados culturais atribuídos às práticas de mobilidade feminina (Souza e Oliveira, 2016). 


\section{A dimensão moral do movimento e a busca por uma vida melhor}

Em trabalhos etnográficos recentes feitos no Brasil, encontramos análises sobre a dimensão moral do movimento e da mudança de lugares como forma de melhorar a vida (Borges, 2003; Rumstain, 2012; Guedes, 2013, 2014; Marques, 2015; Carneiro e Dainese, 2015), ideias e práticas encontradas especialmente entre trabalhadores das classes populares e suas famílias. Temos ainda pesquisas sobre a forma acampamento como descrição da vida precária ao redor do mundo (Agier, 2013, 2014). Áreas de ocupação recente nas cidades brasileiras podem ser comparadas com essas experiências de construir um lar em terrenos que farão parte de uma cidade ou lugar urbanizado no futuro. Assim, devem ser aproximados os dados etnográficos e interpretações sobre estas experiências de mobilidade e habitação (dwelling) (Ingold, 2011a) com os resultados já apresentados pelas pesquisas sobre mobilidades femininas (Uteng e Cresswell, 2008; Jirón, 2010, 2011; Jiménez, 2013; Akyelken, 2013) para extrairmos novas visadas sobre as vivências situadas da mobilidade. Esses trabalhos tendem a se concentrar em áreas adensadas das cidades ou mesmo áreas centrais, com estruturas urbanas de transporte e serviços relativamente consolidadas. O contexto social e geográfico do Jardim Canadá e Água Limpa tem um interesse especial porque se trata de processos de transformação urbana recente em áreas com temporalidades distintas de fabricação de cidades e fases de ocupação de lotes (terrenos para construção), considerando as condições e soluções de mobilidade especialmente para mulheres, mas também para homens e suas famílias. Em síntese, as condições de motilidade (Kaufmann, Bergman e Joye, 2004) de pessoas que vivem nesses lugares estudados podem ser descritas direcionando-se o foco analítico para a constituição das cidades através das práticas de mobilidade e das propriedades morfológicas das fronteiras urbanas (Jensen, 2009; Tanzarn, 2008). Ao falar em motilidades, reforça-se que a pesquisa sobre mobilidades propõe-se a investigar "the relation between human mobilities and immobilities, and the unequal power relations which unenvenly distribute motility, the potential for mobility" (Hannam, Sheller e Urry, 2006, 
p. 15), aspecto melhor evidenciado para os cidadãos mais pobres das bordas dos centros urbanos.

Sob esta perspectiva, entende-se a expansão urbana como processo vivido entre lugares e tempos biográficos dos individuos e suas famílias, considerando-se as estruturas urbanas e suas transformações, quando são resultantes da ação política de moradores e das invenções locais do dia a dia na fronteira.

Um dos aspectos mais notáveis já observado é o ânimo perceptível nas narrativas daquelas pessoas que chegaram há mais tempo nos bairros e contam orgulhosas sobre os percalços e as aventuras passadas para erguer suas casas. Tal como a história de uma moradora de Água Limpa que saia de sua casa em uma região de moradias populares da zona sul de Belo Horizonte, pegava um ônibus até Água Limpa com toda a família levando consigo enxadas e pás para cercar e tomar posse de um lote onde hoje está erguida sua casa.

Essa certeza de estar tomando o caminho certo para sua vida, reconheço ainda na história da moradora que deixou um emprego estável numa grande fábrica de eletrodomésticos em Contagem (MG) e um aluguel caro na região do Barreiro, em Belo Horizonte, para comprar um lote em Água Limpa; conseguiu emprego por um ano na empresa de limpeza que presta serviços para a fábrica da Coca-Cola e estava desempregada quando a conheci no curso de artesanato. Não é raro encontrar no posto de saúde pessoas que moram na parte mais distante do bairro, de ocupação ainda esparsa, que pertence ao município de Itabirito. Nesse local vive uma família com três filhos, na qual o pai e a mãe estão sem trabalho. Têm sorte porque possuem luz elétrica em casa, em comparação com sua vizinha que os acompanhava em visita à assistente social, a qual morava há quatro anos em Água Limpa sem luz elétrica em casa.

Alguns parecem estar em condição de espera porém garantidos em seus lotes e casas ainda improvisadas e pequenas (é comum habitar em apenas três cômodos, alguns feitos de madeirite, que são chapas compensadas de madeira). Mas isso é encarado como 
condição provisória, que aos poucos mudará para melhor, como o ensinam as histórias contadas pelos vizinhos mais estabelecidos no lugar. Por enquanto, esse é um bom lugar para viver, onde o recomeço das histórias se entrelaça com o começo da cidade. Dispor-se a vir para cá é por-se em movimento, valor caro aos sujeitos que outros antropólogos também encontram Brasil afora (por exemplo, Rumstain, 2012; Guedes, 2013).

A compreensão das mobilidades nesses contextos de fronteiras que são cidades em processo implica aproximar-se das lógicas dos atores sociais e abandonar definições prévias da boa cidade e das escolhas acertadas. Assim, uma situação de precariedade pode ser vista como passageira e não desesperadora para quem já se acostumou com as andanças da vida.

Entendo que essa perspectiva interpretativa, fundamental para a pesquisa e o desenho de políticas de mobilidade, acompanha o comentário de Cass, Shove e Urry (2005) de que:

analyses of transport-related social exclusion are tipically based upon a model that views inclusion in terms of people being able to 'get at' pre-defined 'public' goods and services located within pre-determined formal locations/destinations. This model rests on a definition of what excluded people should want or need and obscures the role that social networks play in maintaining a 'good life' and in structuring the meaning of inclusion and participation. (p. 551)

\section{Conclusão}

Os cenários de mobilidade apresentados anteriormente revelam um atravessar constante entre lugares no tempo, seja o tempo biográfico dos indivíduos e suas familias, seja o correr dos dias e seus afazeres entre casas, ruas e estrada. Embora as pessoas até agora entrevistadas sejam primordialmente mulheres de classes baixas, suas experiências não são de confinamento, mesmo quando passam por 
restrições orçamentárias e são constrangidas por obrigações domésticas ou outros compromissos. Pelo contrário, o que se vê são as mulheres se movendo diariamente para trabalhar ou partir em busca de emprego, assistência de saúde e social para si e para suas famílias.

São as mobilidades e imobilidades relativas que fazem do Jardim Canadá e de Água Limpa lugares produzidos por relações, ao invés de espaços dados de uma vez por todas (Jiménez, 2013). Essas fronteiras urbanas, de modo mais sensivel que outros lugares, devem ser conceituados "in terms of process, meaning, and relations to the surroundings, rather than in terms of essence" (Frello, 2008, p. 26). Processos tais que se realizam por meio de trajetos concretos dos moradores e visitantes que estão envolvidos nos mais diversos tipos de movimentos. Para tanto, rastrear os percursos que se fazem entre lugares que são percebidos como "não cidade", característica entendida pelo não-morador como falta e pelo morador como brecha para fazer existir o novo em suas vidas, é o caminho analítico mais promissor. As biografias residenciais dos moradores das fronteiras urbanas ilustram a relevância das imaginações de futuro na vida cotidiana. Aqui se vive o "everyday futurism" (Pels, 2015, p. 783), como se o tempo e o espaço de hoje, em intensidades variadas conforme o grau de estabelecimento de cada família nos bairros tivessem uma atmosfera de "not-yet", de porvir. Mover-se em busca de melhorias para a casa e para a vida de quem nela habita é o meio para fazer acontecer esse espaço-tempo esperado para as pessoas de quem falei nesse trabalho. Nessa empreitada, as mulheres, embora algumas não o façam sozinhas, são agentes que alinhavam as tramas urbanas da vida nesses locais.

\section{Referências}

Adey, P. (2006). If mobility is everything then it is nothing: towards a relational politics of (im)mobilities. Mobilities, 1(1), 75-94.

Agier, M. (2013). Campement urbain. Du refuge naît le ghetto. Paris: Manuels Payot. 
Agier, M. (Dir.). (2014). Un monde de camps. Paris: La Découverte.

Agier, M. (2015). Do direito à cidade ao fazer-cidade. O antropólogo, a margem e o centro. Mana, 21(3), 483-498.

Akyelken, N. (2013). Development and gendered mobilities: narratives from the women of Mardin, Turkey. Mobilities, 8(3), 424-439.

Andrade, L. T. de. (2016). O espaço metropolitano no Brasil: nova ordem espacial? Cadernos $C R H, 29(76), 101-118$.

Andrade, L. T. de, Mendonça, J. G. de e Diniz, A. M. A. (Eds.). (2015). Belo Horizonte: transformações na ordem urbana. Rio de Janeiro - Belo Horizonte: Letra Capital, Observatório das Metrópoles, Editora PUC Minas.

Bhering, I. G. de A. e Monte-Mór, R. L. de M. (2006). Dinâmica do crescimento das cidades brasileiras: pobres periferias ricas. Em H. S. de M. Costa (Org.), Novas Periferias Metropolitanas. A expansão metropolitana em Belo Horizonte (pp. 291-311). Belo Horizonte: C/Arte.

Birman, P., Leite, M. P., Machado, C. e Carneiro, S. de S. (Orgs.). (2015). Dispositivos urbanos e trama dos viventes. Ordens e resistências. Rio de Janeiro: Editora FGV.

Borges, A. (2003). Tempo de Brasilia. Etnografando lugares-eventos da política. Rio de Janeiro: Relume Dumará, Núcleo de Antropologia da Política/UFRJ.

Carneiro, A. e Dainese, G. (2015). Notas sobre diferenças e diferenciações etnográficas do movimento. Ruris, 9(1), 143-166.

Cass, N., Shove, E. e Urry, J. (2005). Social exclusion, mobility and access. The Sociological Review, 53(3), 540-555.

Costa, H. S. de M. (Org.). (2006). Novas Periferias Metropolitanas. A expansão metropolitana em Belo Horizonte: dinâmica e especificidades no Eixo Sul. Belo Horizonte: C/Arte. 
Craveiro, C. e Linhares, L. R. F. (2006). Novas centralidades periféricas no espaço metropolitano belo-horizontino - Seis Pistas e Jardim Canadá. Em H. S. de M. Costa (Org.), Novas Periferias Metropolitanas. A expansão metropolitana em Belo Horizonte: dinâmica e especificidades no Eixo Sul (pp. 423-444). Belo Horizonte: C/Arte.

Cresswell, T. (2010). Towards a politics of mobility. Environment and Planning D: Society and Space, 28(1), 17-31.

Durchfort, J. (2013). Processo anual de atualização de dados: acompanhamento e reflexão sobre a evolução da realidade social do Jardim Canadá e região. Fundação Dom Cabral, Instituto de Desenvolvimento Local Integrado. Nova Lima, Minas Gerais.

Durchfort, J. (2015). A realidade social de Água Limpa: um processo em pleno desenvolvimento. Fundação Dom Cabral, Instituto de Desenvolvimento Local Integrado. Nova Lima, Minas Gerais.

Flamm, M. e Kaufmann, V. (2006). Operationalizing the concept of motility: a qualitative study. Mobilities, 1(2), 167-189.

Frello, B. (2008). Towards a discursive analytics of movement: on the making and unmaking of movement as an object of knowledge. Mobilities, 3(1), 25-50.

Girola, M. F. (2008). Modernidad histórica, modernidad reciente. Procesos urbanos en el Área Metropolitana de Buenos Aires: los casos de Conjunto Soldati y Nordelta (Tesis de Doctorado). Universidad de Buenos Aires, Facultad de Filosofia y Letras, Buenos Aires.

Guedes, A. D. (2013). O trecho, as mães e os papéis. Etnografia de movimentos e durações no norte de Goiás. São Paulo - Rio de Janeiro: ANPOCS, Garamond.

Guedes, A. D. (2014). Fevers, movements, passions and dead cities in northern Goiás. Vibrant, 11(1), 56-95.

Hannam, K., Sheller, M. e Urry, J. (2006). Editorial: Mobilities, immobilities and moorings. Mobilities, 1(1), 1-22. 
Hanson, S. e Pratt, G. (1995). Gender, work, and space. London: Routledge.

Hernandez, D. O. e Titheridge, H. (2016). Mobilities of the periphery: informality, access and social exclusion in the urban fringe in Colombia. Journal of Transport Geography, (55), 152-164.

Ingold, T. (2011a). Building, dwelling, living: how animals and people make themselves at home in the world. In T. Ingold (Ed.), The perception of the environment. Essays on livelihood, dwelling and skill (pp. 172-188). London: Routledge.

Ingold, T. (2011b). Against space: place, movement, knowledge. In T. Ingold (Ed.), Being alive. Essays on movement, knowledge and description (pp. 145155). London: Routledge.

Ingold. T. (2014). That's enough about ethnography. HAU: Journal of Ethnographic Theory, 4(1), 383-395.

Jensen, O. B. (2009). Flows of meaning, cultures of movements - urban mobility as meaningful everyday life practice. Mobilities, 4(1), 139-158.

Jiménez, A. C. (2013). On space as a capacity. The Journal of the Royal Anthropological Institute, 9(1), 137-153.

Jirón, P. (2010). Mobile borders in urban daily mobility practices in Santiago de Chile. International Political Sociology, (4), 66-79.

Jirón, P. (2011). On becoming 'la sombra/the shadow’. In M. Büscher, J. Urry e K. Witchger (Eds.), Mobile Methods (pp. 36-53). London: Routledge.

Kaufmann, V., Bergman, M. M. e Joye, D. (2004). Motility: mobility as capital. International Journal of Urban and Regional Research, 28(4), 745-756.

Kusenbach, M. (2003). Street phenomenology. The go-along as ethnographic research tool. Ethnography, 4(3), 455-485. 
Larsen, J., Axhausen, K. W. e Urry, J. (2006). Geographies of social networks: Meetings, travel and communications. Mobilities, 1(2), 261-283.

Law, R. (1999). Beyond 'women and transport': towards new geographies of gender and daily mobility. Progress in Human Geography, 23(4), 567-588.

Leiva, G. de C. (2015). Viagens intrametropolitanas casa-trabalho na RMBH. Em L. T. de Andrade, J. G. de Mendonça e A. M. A. Diniz (Eds.), Belo Horizonte: transformações na ordem urbana (pp. 215-234). Rio de Janeiro - Belo Horizonte: Letra Capital, Observatório das Metrópoles, Editora PUC Minas.

Little, J., Peake, L. e Richardson, P. (Eds.). (1988). Women in Cities. Gender \& The urban environment. London: Macmillan.

Marques, A. C. (2015). Movimentos em família. Ruris, 9(1), 3-37.

Massey, D. (2013). Pelo espaço. Uma nova politica da espacialidade. Rio de Janeiro: Bertrand Brasil.

Mont'alvão Neto, A. L. (2009). Deslocamentos urbanos e desigualdades sociais: um estudo do movimento diário da população de Belo Horizonte (Dissertação de Mestrado). Universidade Federal de Minas Gerais, Programa de Pós-graduação em Sociologia, Belo Horizonte.

Motta, E. (2014). Houses and economy in the favela. Vibrant, 11(1), 118-158.

Moura, C. P. de. (2010). Condomínios e gated communities: por uma antropologia das novas composições urbanas. Anuário Antropológico 2009, (II), 209-232.

Ojima, R., Marandola Jr., E., Pereira, R. e Silva, R. (2010). O estigma de morar longe da cidade: repensando o consenso sobre as 'cidades-dormitório' no Brasil. Cadernos Metrópole, 12(24), 395-415.

Pels, P. (2015). Modern times. Seven steps toward an anthropology of the future. Current Anthropology, 56(6), 779-796. 
Pétonnet, C. (1982). L'Observation flottante, L'exemple d'un cimetière parisien. L'Homme, 22(4), 37-47.

Pires, C. T. P. (2003). Evolução do processo de ocupação urbana do município de Nova Lima: um enfoque sobre a estrutura fundiária e a produção de loteamentos (Dissertação de mestrado). Universidade Federal de Minas Gerais, Belo Horizonte.

Pires, L. (2013). Transportes públicos e representações sobre mobilidade social: possiveis percepções a partir do Rio de Janeiro e de Buenos Aires. Anuário Antropológico 2012, 165-193.

Rumstain, A. (2012). Peões no trecho. Trajetórias e estratégias de mobilidade no Mato Grosso. Rio de Janeiro: E-papers.

Souza, C. V. e Oliveira, M. F. de. (2016). Los espacios de movilidad urbana de las mujeres y los significados de las restricciones sociales, culturales y materiales. En A. Martínez e N. A. G. Serrudo (Eds.), La sociabilidad y lo público: experiencias de investigación (pp. 336-370). Bogotá: Editorial Pontificia Universidad Javeriana.

Souza, J. de. (2015). Organização social do território e os movimentos pendulares na RMBH. Em L. T. de Andrade, J. G. de Mendonça, e A. M. A. Diniz (Eds.), Belo Horizonte: transformações na ordem urbana (pp. 178-211). Rio de Janeiro - Belo Horizonte: Letra Capital, Observatório das Metrópoles, Editora PUC Minas.

Tanzarn, N. (2008). Gendered mobilities in developing countries: the case of (urban) Uganda. In T. P. Uteng e T. Cresswell (Eds.), Gendered Mobilities (pp. 159-171). Hampshire: Ashgate.

Telles, V. da S. (2010). A cidade nas fronteiras do legal e do ilegal. Belo Horizonte: Fino Traço.

Thrift, N. (1999). Steps to an ecology of place. In D. Massey, J. Allen e P. Sarre (Eds.), Human Geography Today. Cambridge: Polity Press. 
Ureta, S. (2008). To move or not to move? Social exclusion, accessibility and daily mobility among the low-income population in Santiago, Chile. Mobilities, 3(2), 269-289.

Uteng, T. P. e Cresswell, T. (Eds.). (2008). Gendered Mobilities. Hampshire: Ashgate.

Vega Centeno, P. (2010). Movilidad y vida cotidiana de mujeres del sector popular de Lima. Un análisis del testimonio de la señora Eufemia. Anthropologica, (22), 31-62.

Woortmann, K. (1982). Casa e família operária. Anuário Antropológico, 80, 119-150.

\section{Cómo citar este artículo}

Souza, C.V. (2018). A vida móvel das mulheres entre os bairros e as cidades: explorações antropológicas em fronteiras urbanas da Região Metropolitana de Belo Horizonte (Minas Gerais/Brasil). Universitas Humanística, 85, 293-318. https://doi.org/10.11144/Javeriana.uh85.vmmb 